Клевцов, 2008 г.

3. ВРД 39-1.10-052-2001 Методические указания по выбору и применению асинхронного частотно-регулируемого электропривода мощностью до 500 кВТ

\title{
Анализ эксплуатационных параметров электромобилей в условиях низких температур
}

Григорьев С.И., студент,

Северо-Восточный федеральный университет, 2. Якутск

E-mail: wanqod7596@gmail.com

Научный руководитель: магистр-инженер, старший преподаватель Анисимов Е.Е.

В настоящее время продолжает расти интерес к электромобилям в мире, особенно в странах Европы и Америке. Так производство электромобилей в мире выросло с 240 тыс. электромобилей в 2013 году до 400 тыс. в 2014 году. А по прогнозу энергетического центра московской школы управления “Сколково” продажи электромобилей к 2020 году вырастут до 7,2 млн. электромобилей. [1] Согласно прогнозу Международного энергетического агентства рынок электромобилей активно будет возрастать, что хорошо показано на рисунке 1. [2]

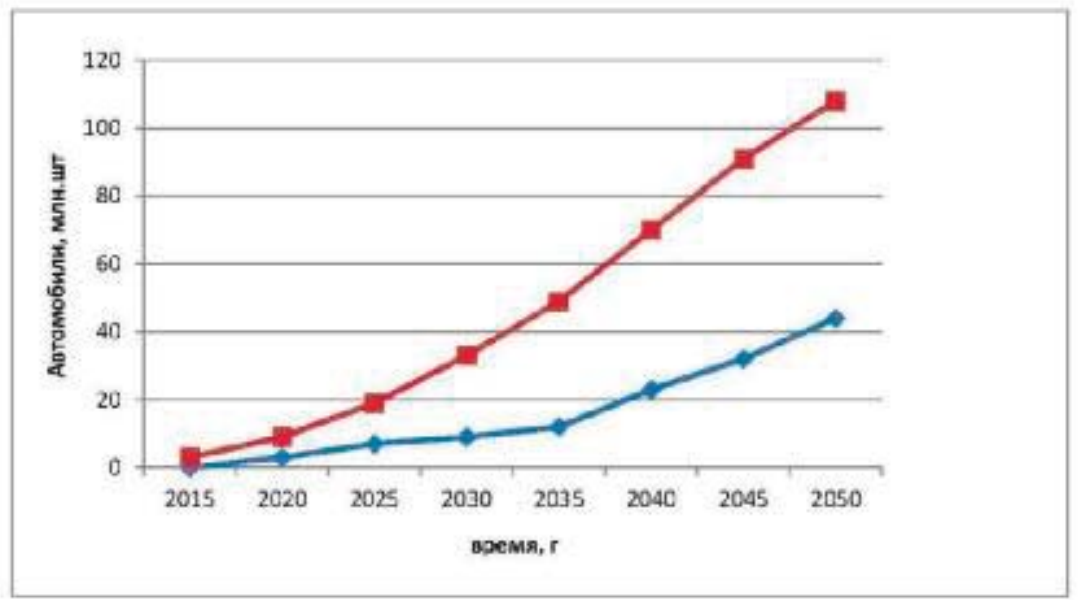

Рис. 1. Прогноз мировых продаж автомобилей, использующих электроэнергию: 1) гибридные автомобили; 2) электрические автомобили 


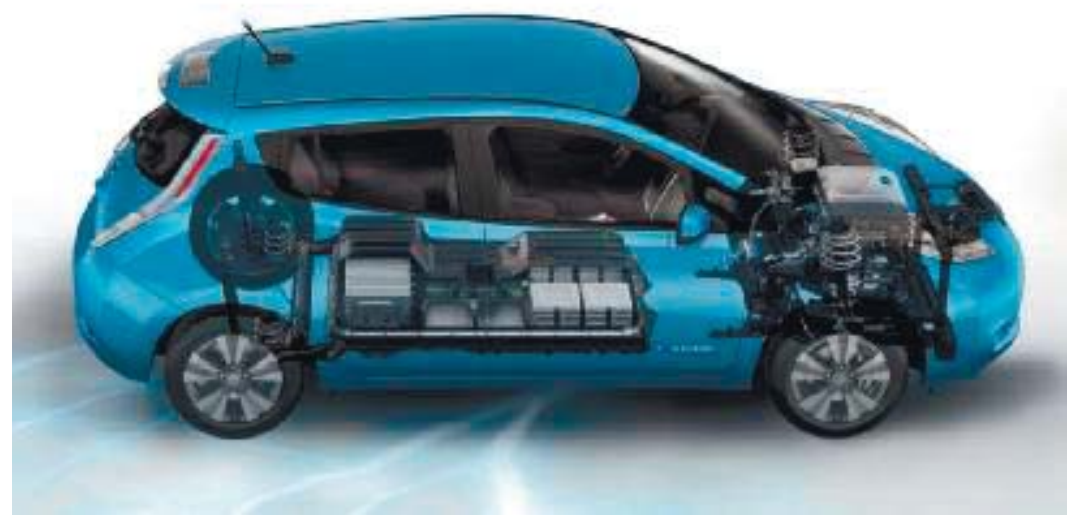

Рис. 2. Схема электромобиля Nissan Leaf

Под капотом расположен электродвигатель мощностью 80 кВт (около 108 л. с.), чей крутящий момент достигает $280 \mathrm{H} \cdot$ м. Привод электромобиля - передний. Нижнее расположение самого тяжёлого элемента автомобиля - аккумуляторной батареи обеспечивает лучшую устойчивость по сравнению с одноклассниками. Кроме этого, батарея также обеспечивает более высокую жёсткость конструкции для пяти-дверных хэтчбеков подобной конструкции. Ёмкости батареи 24 кВт·ч и возможностей рекуперативного торможения хватает (по оценкам представителей Nissan) на 160 км пробега. Жизненного цикла батарей, по предварительным оценкам, должно быть достаточно минимум на 5 лет.

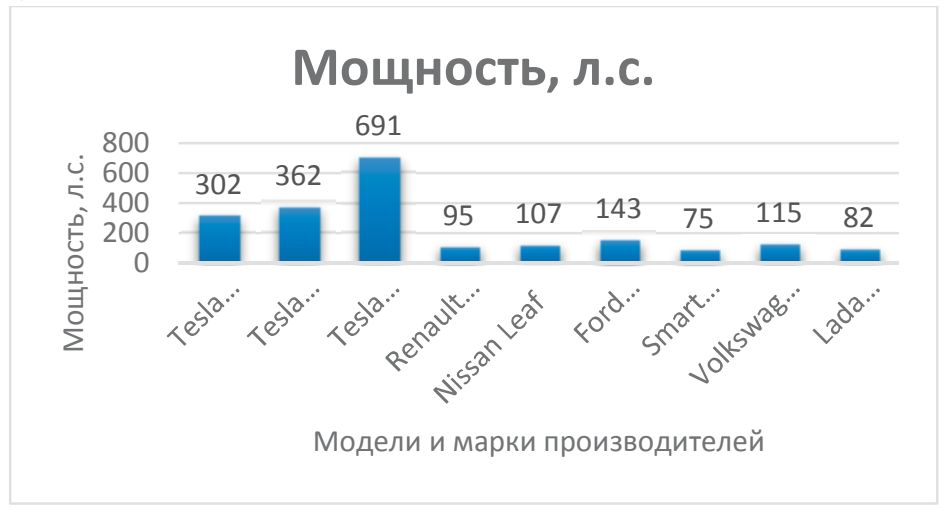

Диаграмма 1. Сравнение мощности электродвигателей

По диаграмме видно, что электромобиль Tesla Model S опережает по мощности другие известные марки электромобилей.

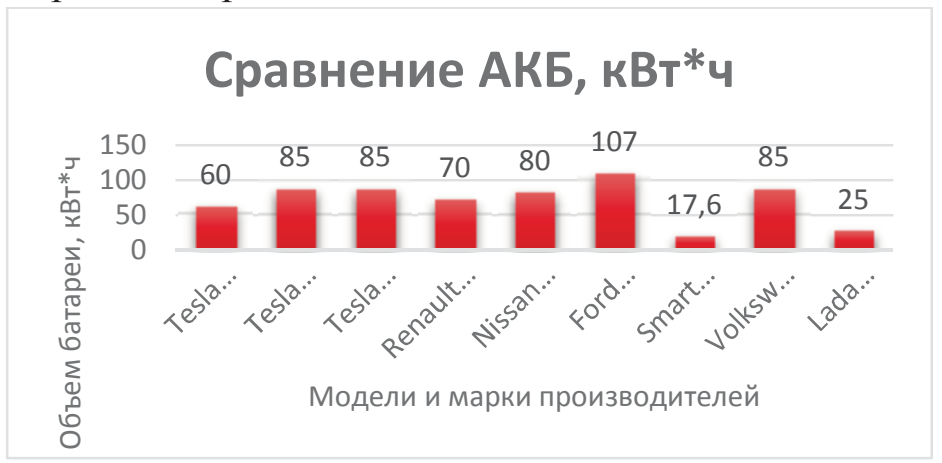

Диаграмма 2. Сравнение объема батареи электромобилей 
По диаграмме видно, что электромобиль Ford Focus Electric опережает по объему батареи своих представителей.

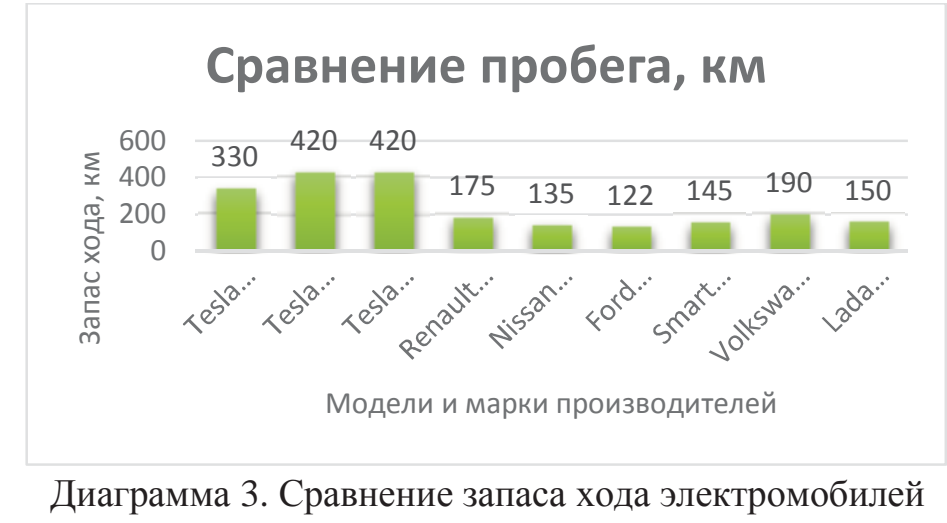

В диаграмме показаны запас хода электромобилей из них выдвигается вперед Tesla Model S.

Из перечисленных агрегатов автомобиля важными эксплуатационными составляющими являются электродвигатель и аккумуляторная батарея.

Нами проводится мониторинг типов аккумуляторов, используемых в электромобилях. С помощью полученных параметров произвели теоретическое сравнение типов аккумуляторов. [3]

Были выявлены следующие типы аккумуляторов, использующихся в электромобилях:

- Свинцово-кислотный аккумулятор: КПД - 80-90\%, рабочая температура может колебаться в пределах от - 40 до +40 градусов Цельсия, напряжение разряженного аккумулятора - 1.8 Вольт, ЭДС заряженного аккумулятора 2.18 Вольт, напряжение - 2 Вольта, энергоёмкость - 30-60 ВТч\кг. Цикл жизни составляет 1000-1500 разряд\заряд батареи.

- Литий-ионный аккумулятор: напряжение заряженного элемента - 4.2 Вольта, напряжение разряженного - 2.75 Вольта, температурный режим - -20 до +60 градусов Цельсия, время заряда - 2-4 часа. Цикл жизни - свыше 1000 разряд/заряд аккумулятора.

- Натрий-никель-хлоридный аккумулятор: рабочая температура - -40 - + 300 градусов Цельсия, энергоемкость - 730 ВТч/кг, ЭДС - 2.6 Вольта. Цикл жизни - более 1000 разряд заряд аккумулятора.

- Никель-кадмиевый аккумулятор: Рабочая температура от -50 до +40 градусов Цельсия, напряжение рабочее - 1, 3 Вольта, ЭДС - 1.37 Вольта, мощность 150-500 Вт\кг, энергоемкость - 65 Втч\кг. Цикл жизни - свыше 1000 разряд \заряд аккумулятора.

Учитывая технические характеристики нами был проведен анализ работы аккумуляторов в Крайнем Севере. 


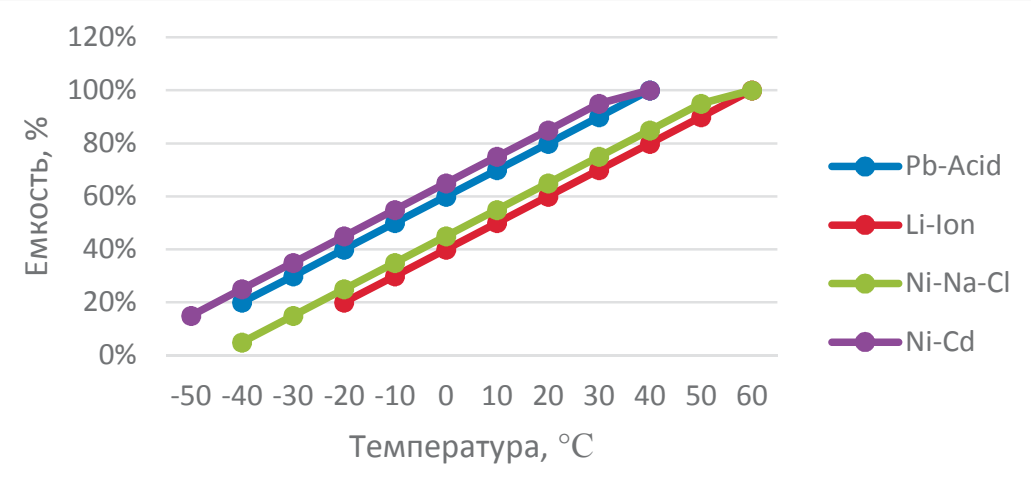

График 1. Примерное изменение емкости аккумулятора от температуры

В настоящее время многие водители, которые хотят пересесть на электромобиль, задаются вопросом как же они ведут себя в мороз. Как пример был взят электромобиль Nissan Leaf.

Производители говорят, что пробег будет составлять 135 км при полной зарядке. Но реальный пробег зависит от нескольких факторов:

- Температура внешней среды

- Использования печки

- Место стоянки (на улице или в теплом гараже)

Реальный пробег составляет от 40-120 км при полном заряде АКБ. Причина в том, что печка потребляет в 3-5 раза питания чем кондиционер, сюда же включаем большой расход фар, большое сопротивления качению зимой.

При -15С большинство водителей проезжают 70-80 км при полном заряде АКБ, а при -25С до -30С производительность «бортовой энергетики» падает, то есть пробег составит 40-50 км. Соответственно есть и плюсы использование электромобиля в зимнее время:

- Прогрев салона занимает от 1-2 минут

- Электромотору лучше, когда холодно

- Существует подогрев сидений и руля

- Управляемость значительно выше, благодаря рекуперации. [4]

Перегрев электродвигателя всего на 10 градусов сокращает срок службы изоляционных материалов в два раза. Следующие 10 градусов укорачивают этот показатель еще в два раза. В итоге при перегревании электродвигателя на 40 градусов срок эксплуатации изоляции сокращается в 32 раза, что делает ресурс оборудования настолько минимальным, что его применение становится нерентабельным. [5]

От сюда следует, что эксплуатация электромобиля в Крайнем Севере возможно при правильной эксплуатации, то есть:

- АКБ следует держать в тепле

- Избегать долгих простоев не заведенного автомобиля на морозе (более 30 минут)

- Прогрев автомобиля после долгого простоя на морозе желательно при подключении к сети, а не от батареи

Проблема эксплуатации электромобилей является АКБ, что в дальнейшем для решения данной проблемы будут проведены испытания электромобиля в районах Крайнего Севера и будут представлены способы сохранение тепла АКБ без потерь емкости, запаса хода и мощности. 
При большом интересе к электромобилям появляется проблема зарядки автомобиля в электро-заправочных станциях в районах Крайнего Севера. Например, возьмем город Якутск. В городе отсутствуют электро-заправочные станции, но уже есть гибриды и в скором времени будут электромобили. Для решения данной проблемы в автодорожном факультете была построена электропарковка для зарядки электромобилей и электро-подогревающее оборудование для двигателя внутреннего сгорания.

\section{Список литературы:}

1. Антоненков В.О., Цыганков Д.В., Лукашков Н.И. Рост интереса к электромобилям в мире // Новая наука: стратегии и векторы развития / ООО "Агентство международных исследований". Уфа, 2015. - С. 119 - 121.

2. Свиридов С.А., Хатина И.В. Электромобили: достоинства и недостатки // Современные автомобильные материалы и технологии (Самит - 2015) Курск, 27 ноября 2015 г. / ЗАО «Университетская книга». Курск, 2015. - С. 212 - 215.

3. Родовид М.3. Как ведут себя электромобили Nissan Leaf зимой [Электронный pecypc] - Режим доступа: http://rodovid.me/electrocar/nissan_leaf_zimoy.html

4. Нагрев электродвигателей, его причины и влияние на срок службы [Электронный ресурс] - Режим доступа: http://cable.ru/articles/id-1077.php

\section{Определение тока короткого замыкания в цепи}

\section{Жиндаева В.О., студентка, Чукотский филиал Северо-Восточного федерального университета, 2. Aнадырь, E-mail: v.jindaewa@yandex.ru \\ Научный руководитель: к.т.н., профессор Королюк Ю.Ф.}

Предлагается программа расчета токов короткого замыкания в произвольной электрической сети, содержащей произвольное число генераторов, трансформаторов и линий электропередач. Программа составлена в системе MathCad и использует метод узловых напряжений.

$$
\mathrm{I}=\mathrm{Y} * \mathrm{U}
$$

где I, U - столбцовые матрицы токов и напряжений соответственно;

$\mathrm{Y}$ - квадратная матрица проводимостей сети.

С этой целью для каждого вида элементов составлена процедура, позволяющая по паспортным данным вычислить элементы схемы замещения. Пассивных элементов, отличающихся друг от друга два, а значит и процедур тоже две. Учет $\mathbf{n}$ элементов сети в программе осуществляется обращением $\mathbf{n}$ раз к соответствующим процедурам.

Уравнение схемы замещения линии электропередачи:

$$
\begin{aligned}
& \mathrm{I}_{\mathrm{m}}=\mathrm{Y}_{\mathrm{m}, \mathrm{m}} \cdot \mathrm{U}_{\mathrm{m}}-\mathrm{Y}_{\mathrm{m}, \mathrm{n}} \cdot \mathrm{U}_{\mathrm{n}} \\
& \mathrm{I}_{\mathrm{n}}=-\mathrm{Y}_{\mathrm{m}, \mathrm{n}} \cdot \mathrm{U}_{\mathrm{m}}+\mathrm{Y}_{\mathrm{n}, \mathrm{n}} \cdot \mathrm{U}_{\mathrm{n}}
\end{aligned}
$$

Трансформатор замещается как каскадное соединение двух четырехполюсников: сопротивления, приведенного к одной из сторон и идеального коэффициента 